\title{
La cárcel y el carcelero de la mujer colonial ${ }^{1}$
}

PABLO LACOSTE*

\begin{abstract}
Resumo: O problema da subordinação da mulher na América Latina colonial tem levado ao estudo da vítima, mas não ao vitimário. Convém examinar o papel do carcereiro, isto é, do ator social que se ocupa de encarcerá-la e mantê-la na prisão. O presente artigo identifica quatro possíveis carcereiros: o pai, o marido, o clérigo e o caçador de viúvas. Também se definem os cárceres em que se confinava a mulher: a casa, a prisão material, o purgatório e a pobreza. Estes cárceres e os carcereiros formavam um sistema, com seus próprios códigos e normas de funcionamento.

Abstract: This paper discuses the problem of the subordinated situation of Latin American colonial woman, since a new and original point of view: her prison and her jailer. The essay tries to demonstrate that colonial woman use to have four wardens: her father, her husband, the clergy and the widow's hunter. They used to utilize four jails to imprison her: the domestic jail (home), the socioeconomic one (poverty), the real prison (with walls and grates) and the ideological one (purgatory). Sometimes, the colonial woman's live was restricted to jump from one prison to an other.
\end{abstract}

Palavras-chave: Mulher colonial. Prisão feminina. Carcereiro de mulheres.

Key words: Colonial woman. Women's prison. Women's jailer.

\section{La cárcel y el carcelero de la mujer colonial}

La mujer colonial latinoamericana fue una actriz social subordinada y muchas veces, victimizada por el sistema. La literatura especializada ha podido describir y explicar numerosos casos de discriminación, maltrato y condiciones de vida desfavorables. Por tal motivo, para realizar su potencial económico o cultural, la mujer debía refugiarse en el convento o bien, enfrentar grandes barreras en el mundo. ${ }^{2}$ Estos obstáculos operaban en forma

1 Este trabajo se ha realizado en el marco de la ejecución del proyecto 1051109 de FONDECYT - Chile.

Universidade de Talca, Chile. E-mail: placoste@utalca.cl

2 Susan Socolow. The women of Colonial Latin America. Durham/London: Cambridge University Press, 2000. Kimberley Gauderman. Women's Lives in Colonial Quito.

Estudos Ibero-Americanos. PUCRS, v. XXXIII, n. 2, p. 7-34, dezembro 2007 
persistente para limitar sus capacidades de movimiento. El sistema tendía encerrarla para controlarla mejor.

Por lo general, el estudio de la situación de la mujer se ha centrado en la víctima, prestando menor atención al victimario. La mayor parte de los libros y artículos sobre el tema se han centrado en ella, la cautiva, no así en él, el carcelero. Se dispone de un amplio conocimiento acerca de los condicionantes que tenía la mujer-víctima, pero sabemos menos del hombre-victimario. ¿Por qué actuaba de esa forma? ¿Cuáles eran las presiones ideológicas y culturales que también limitaban la capacidad de acción del varón, para llevarlo a ejercer violencia sobre la mujer? ¿Qué sentía el hombre al tener que castigar a su mujer? Nos preguntamos sobre la posibilidad de una tensión emocional dentro del corazón de ese hombre. Deseamos saber si él mismo no experimentaba una violencia interna, cuando la ideología vigente lo conducía a tomar medidas contra una mujer amada.

Paralelamente al estudio de los casos particulares, el presente artículo propone una explicación que pueda resultar de utilidad para comprender el funcionamiento del sistema en América colonial. En ese sentido, se propone que el encierro de la mujer colonial estaba determinado principalmente por cuatro actores sociales que operaban como carceleros. A su vez, ellos tenían espacios precisos (reales o ideológicos) en los cuales encerrar a la mujer.

Los cuatro carceleros eran el padre, el marido, el clérigo y el cazador de viudas. Las cárceles eran la casa, la prisión material, el purgatorio y la pobreza. Con estos elementos podemos sintetizar una parte importante de los verdugos y los lugares de encierro que se usaron con la mujer latinoamericana durante 300 años, tendencia que se mantuvo relativamente vigente en el siglo XIX y se fue revirtiendo - parcialmente - en el XX.

Los espacios que usaban los carceleros eran usualmente, uno principal y otro alternativo. La prisión principal que usaban el padre y el marido, era la misma casa, como espacio del encierro doméstico. El clérigo usaba como cárcel al purgatorio; y el cazador de viudas podía encerrarla en la pobreza. Pero junto con estos

Gender, Law and Economy in Spanish America. Austin: University of Texas Press, 2003. Ann Twinam. Public lives, private secretes. Gender, honor, sexuality and illegitimacy in colonial Spanish America. Stanford, California; Stanford University Press, 1999. Kathryn Burns. Colonial habits. Convents and the spiritual economy of Cuzco, Perú. Durham/London: Cambridge University Press, 1999. Boyer, Richard and Spurling, Geoffrey (eds.). Colonial lives. Documents on Latin American History, 1550-1850. Oxford University Press, 2000. Bernard Levalle. Amor y opresión en los andes coloniales. Lima: IEP, 2000. 
espacios principales, estaban los alternativos. Tanto el padre como el marido, podían usar la pobreza como espacio de castigo para la mujer díscola. En caso de desacatar su autoridad, podían desheredarla privarla de bienes. El clérigo también podía actuar en esa dirección. Paralelamente, el uso de la cárcel material, como edificio con muros y rejas, también podía ser usado por el marido, promovido o legitimado por el clérigo y, algunos casos, el padre.

La situación de la mujer, como sujeta a un encierro permanente por su propio bien, desde la perspectiva de los varones, se garantizaba por el mecanismo del casamiento, por el cual la mujer pasaba de la autoridad del padre a la autoridad del marido. El padre se sentía con pleno derecho a decidir con quién debía casarse su hija. Si ésta violaba esta norma, el padre estaba autorizado a usar mecanismos de castigo. Si la hija trataba de eludir la cárcel del matrimonio indeseado, el padre usaba la cárcel alternativa, que era la pobreza. En América Colonial hay varios casos que ilustran esta situación. Este fue el caso, por ejemplo, don Francisco Quijada, hacendado ganadero, vecino de Pequén, en el Partido del Maule. Su hija María Josefa se reveló contra su autoridad y no aceptó casarse con el novio elegido por el padre. Las malas relaciones se mantuvieron durante varios años, incluso después de la boda y del nacimiento de la sucesión. La ruptura llegó al nivel que la mujer tomó la decisión de tomar dinero de su padre sin su consentimiento. Al redactar su testamento, don Francisco incluyó una cláusula en la cual, explícitamente, mantenía en firme su voluntad de privar de bienes a su hija, a la cual también acusaba de haberle despojado de dinero. En efecto, el documento menciona a María Josefa para luego afirmar que: "la dejo desheredada por ocasión de no haberme dado gusto en casarse con quien yo quería y después de haberme robado $\$ 400$ en plata". ${ }^{3}$ Para compensar esta drástica medida, el testador le dejó un patronal al nieto, junto a otros bienes. ${ }^{4}$ Una situación parecida ocurrió del otro lado de la cordillera, en la ciudad de San Juan de la Frontera, en la provincia de Cuyo. En este caso, el padre autoritario fue don José Antonio Álvarez. Su hija Casilda se reveló contra su voluntad, y contrajo matrimonio con don Francisco Martínez. El padre nunca fue capaz de aceptar que su hija decidiera por si misma. Mantuvo esta posición a lo largo del

3 Testamento de Francisco Quijada, Pequen, 20 de abril de 1731. Archivo Nacional, Notariales de Talca, volumen 4, folios 287.

4 Testamento de Francisco Quijada, Pequen, 20 de abril de 1731. Archivo Nacional, Notariales de Talca, volumen 4, folios 286-290. 
tiempo, hasta el momento de redactar su testamento. En efecto, al redactar este documento, el hacendado incluyó una cláusula en la cual "declaro que a mi hijo Pedro Pablo y a Doña Magdalena están casados y también doña Casilda con Don Francisco Martínez y está casada a disgusto mío, por cuyo motivo es mi voluntad que no le cupiere de legítimo herencia se le den en frutos de la viña en términos de 4 años". 5

Junto con la cárcel socioeconómica (pobreza), se usaba también la cárcel moral o ideológica. Este era el papel del purgatorio, lugar que esperaba a las almas de las personas después de la muerte. Se caracterizaba porque allí se experimentaban sufrimientos atroces, equivalentes a los del infierno. La única diferencia entre el purgatorio y el infierno se hallaba en que éste era eterno mientras aquel tenía un momento de terminación. Pero se ignoraba el tiempo que el alma podía permanecer en esta situación. Ante esta amenaza, los clérigos recomendaban a las mujeres mantener una conducta acorde con los preceptos de la Santa Madre Iglesia, a fin de eludir el purgatorio. En el discurso religioso, se explicaba que por cometer un solo pecado, se podía merecer el castigo eterno en el infierno; pero mediante el sacramento de la confesión, se podía permutar esa pena eterna por una temporaria, que implicaba un tiempo de purificación en el purgatorio. Este enfoque se fortalecía cuando se cometía un pecado con categoría de escándalo, en el sentido de servir de mal ejemplo y, potencialmente, ser causa del pecado de terceros. En tal caso, la gravedad de los castigos se incrementaría sensiblemente. Por tal motivo, si la mujer incurría en una conducta escandalosa, estaba condenada a un largo periodo de sufrimientos en el purgatorio. En estas circunstancias, muchas mujeres se preocupaban muy especialmente en adquirir gracias especiales y lucrar indulgencias, sobre todo las misas que se pudieran celebrar por la salud de su alma, después de su muerte. Los costos estaban tarifados: la misa rezada valía un peso; la misa cantada dos pesos. Para garantizarse una misa semanal, había que fundar una capellanía que produjera una renta de $\$ 52$ anuales, lo cual implicaba gravar una propiedad con un capital de más de $\$ 1.000$ de principal. Estas tarifas fueron normalmente aceptadas por la sociedad hispanocriolla, y el sistema funcionó con notable eficiencia. Así lo detectaron los viajeros y cronistas de la época.

5 Testamento de don José Antonio Álvarez. San Juan, 1 de agosto de 1774. Archivo Histórico de San Juan, Archivo de Tribunales, Libro Joseph Sebastián de Castro, Protocolo 1774, Folio $102 \mathrm{v}$. 
Entre ellos cabe mencionar a Félix Azara el cual, al referirse a las costumbres del cono sur a fines del siglo XVIII, señaló al respecto:

Muchas personas, sobre todo los eclesiásticos y las viejas, fundan durante su vida o por testamento un gran número de capellanías laicas o eclesiásticas a favor de conventos o de particulares, imponiéndoles la obligación de decir o hacer decir algunas misas. ${ }^{6}$

Si bien el dogma del purgatorio valía para todos los vecinos (hombres y mujeres), quienes más lo vivían como una amenaza eran las mujeres. Dada la situación de encierro que debían vivir en sus hogares, las mujeres tenían menos acceso a otras formas de entender la vida; la religión ocupaba un espacio relativamente mayor en sus vidas. La prédica del clérigo era más intensa en el alma de ellas. Por estos motivos, entre otros, el mencionado cronista detectó que las mujeres estaban más preocupadas que los varones por la amenaza del purgatorio. Para ellas, este sitio tenía mayor probabilidad de funcionar como cárcel.

Las cárceles y los carceleros no formaban compartimentos estancos en la vida de la mujer colonial. Al contrario, estaban articulados como en un sistema, que operaba con su propia dinámica. Para comprender el funcionamiento de este sistema, se ha tomado un caso particularmente relevante. Conocida es la historia de doña Tomasa Ponce de León, bella mujer de la élite del Reino de Chile, casada con un próspero militar y viticultor. Tras revelarse, ella fue encerrada en una cárcel privada y, despojada de sus bienes con lo cual, quedó condenada a morir en la pobreza. ${ }^{7} \mathrm{Su}$ vida fue pasar de una cárcel a otra: del encierro en la casa paterna, pasó a la hacienda del marido y de allí a una cárcel privada. Tras enviudar pasó a vivir transitoriamente en libertad, para caer nuevamente en otra prisión de tipo socioeconómica. En este proceso, jugaron los cuatro carceleros: el padre que la entregó al marido; el marido, que la encerró en la cárcel; el cazador de fortunas, que la abandonó en la pobreza; y el clérigo, que avaló y reforzó todo ese trayecto.

En enero de 1718, doña Tomasa se casó con don Miguel de Arizmendi. En ese momento, pasó de la autoridad de su padre, a la del marido. De acuerdo a los usos y costumbres de la época, su padre no la consultó, sin que decidió por si mismo, el destino de su

6 Félix de Azara. Viajes por la América Meridional. Traducida del francés por Francisco de las Barras de Aragón (Madrid: Calpe, 1923), p. 2, 167.

7 Pablo Lacaste. Cárcel y oscuridad para la mujer humana, oro y honores para la mujer divina: triángulo amoroso-religioso en el Reino de Chile, siglo XVIII. CLAHR 12, 4 (fall 2003), p. 447-478. 
hija. Y la joven doncella de 15 años, se casó con un hombre de más de 40. Del encierro relativamente suave (pero encierro al fin), de su casa paterna, la mujer pasaba a lo que terminaría en un encierro duro, en la hacienda de su marido. Nos enfocamos precisamente en este caso.

Sare era una pequeña aldea de los pirineos atlánticos, en el Reino de Baja Navarra, corona de Francia. ${ }^{8}$ Allí nació Miguel de Harizmendy en la década de $1670.9^{9}$ Vivió su infancia y la primera parte de su vida de adulto en su ciudad natal. Aprendió a hablar, leer y escribir en francés, su lengua materna. Llegó a participar en círculos sociales y ceremonias protocolares; fue testigo en varios actos sociales de su comunidad. Se sabe que vivió allí, al menos, hasta 1710.10 Paralelamente, don Miguel fue un marino relativamente destacado; estuvo a cargo de una fragata, en la cual desplegó actividades de seguridad en las costas francesas entre 1712 y $1713 .{ }^{11}$

La migración a América se produjo poco después. Posiblemente viajó en el navío León Franco, el cual zarpó del puerto de Cádiz en 1716, con un nutrido grupo de vascos formado por Juan José de Anzorena (Vizcaya), Juan Bautista de la Reta (de Guipúzcoa) y Manuel Zarazua (Vizcaya), entre otros paisanos. El objetivo era llegar hasta el Callao, pero el barco solo llegó a Buenos Aires, donde se perdió. Los viajeros siguieron su viaje por tierra y algunos de ellos se radicaron en Mendoza. ${ }^{12}$

8 Actualmente Sare pertenece a Bidasoa, y sigue comprendida dentro de Baja Navarra, Francia.

9 En 1697 Arizmendi fue testigo de dos matrimonios y de una operación de compra venta. Libro de bautizos, matrimonios y enterramientos, año 1697. Archivo de la Biblioteca Municipal de Bayona, Sección Genealogía, Microfilm 5 Mi 504, bobina 3, Sare.

Para actuar de testigo era necesaria la mayoría de edad. Por lo tanto, debió nacer en la década de 1670. Lamentablemente, en los archivos parroquiales de Sare no ha quedado registro de su bautizo debido, tal vez, a alguno de los tres incendios que sufrió el repositorio (Documentación aportada por el investigador genealógico Alfonso Ganuza Arizmendi).

10 La permanencia de Arizmendi en Sare hasta 1710 está probada por dos defunciones en las cuales fue testigo, fechadas 3 y 15 de setiembre de 1710, respectivamente. $\mathrm{Li}$ bro de enterramientos, años 1654-1792. Archivo de la Biblioteca Municipal de Bayona, Sección Genealogía, Microfilm 5 Mi 504, bobina 3, Sare (Documentación aportada por el investigador genealógico Alfonso Ganuza Arizmendi).

11 Apresamiento de barco holandés; Memorial de Miguel de Arizmendi, capitán de la fragata "Cantabriene", 30 de enero de 1713. Archivo Histórico Nacional de Madrid, Sección Estado, documento esp 28001101000010302595.

12 Expediente matrimonial de Juan José de Anzorena. Mendoza, 29 de enero de 1721. Archivo del Arzobispado de Mendoza (en adelante AAM), Expedientes Matri- 
El asentamiento en Mendoza significó un cambio importante. Michel Harizmendi se transformó en don Miguel de Arizmendi. Aprendió el español y, en relativamente poco tiempo, compró propiedades en lugar central. Instaló su casa a tres cuadras de la plaza, frente a los terrenos de la distinguida familia de los Ponce de León. La vecindad le permitió entrar en contacto con ellos y casarse con la atractiva Tomasa Ponce de León.

Don Miguel de Arizmendi puso en marcha sus establecimientos vitivinícolas, para elaborar vinos y aguardientes que distribuía en un amplio mercado ubicado 200 leguas al este de sus viñas, en la emergente Buenos Aires. Llegó a elaborar vinos de alta calidad, aspecto en el cual alcanzó un notable liderazgo. ${ }^{13}$ En este marco, don Miguel echó las bases para convertirse en una gran figura regional, con cierto paralelismo con el modelo que Burckhardt asociaba con el príncipe italiano del renacimiento. ${ }^{14}$

Está claro que las comparaciones tienen siempre muchas diferencias, sobre todo si se llega al atrevimiento de relacionar líderes de la Italia renacentista con el barroco americano. Pero, mutatis mutandis, los hechos demuestran que había también muchos elementos en común, sobre todo si se examinan algunos detalles. Burckhardt se refiere a un caso concreto que resulta de interés para el presente estudio:

Ercole celebraba el aniversario de su advenimiento al poder con una procesión que explícitamente se compara con la del Corpus (Christi); hasta la última tiendecita estaba cerrada como si fuera domingo, y en medio del cortejo figuraban todos los miembros de la Casa del Este en áuras vestiduras. ${ }^{15}$

El uso de las procesiones para afirmar el prestigio personal fue, exactamente, lo que hizo Miguel de Arizmendi en Mendoza. Para ello eligió su propia devoción personal (la Virgen del Rosario) y procuró instalarla en el centro del escenario sociocultural de su ciudad. Y en esa procesión, igual que en la Italia renacentista, debía haber vestiduras elegantes que dieran el toque de brillo,

moniales. Expediente matrimonial de Jorge Marquesano, Mendoza, 13 de febrero de 1727. AAM, Expedientes Matrimoniales.

13 Pablo Lacaste. Vino y aguardiente "a la vela": calidad en la empresa vitivinícola colonial, Mendoza siglo XVIII” (Talca, inédito, 2006).

14 Jacobo Burckhardt. La cultura del Renacimiento en Italia (Primera edición en español: Madrid, Losada, 1942; traducción de Ramón de la Serna y Espina; edición consultada: Madrid: Edaf, 1982), p. 12.

15 Jacobo Burckhardt, La cultura del Renacimiento en Italia (Primera edición en español: Madrid, Losada, 1942; traducción de Ramón de la Serna y Espina; edición consultada: Madrid: Edaf, 1982), p. 12. 
solemnidad y pompa a la celebración. Pero más allá de estos detalles, lo importante es que esta historia nos muestra un siglo XVIII lleno de inquietudes, búsquedas y sensibilidades, con sus aspectos autoritarios y tradicionalistas, pero también sus espacios de libertad creativa tanto en lo tecnológico como en el plano de las artes.

La posición económica de Arizmendi se ubicaba cerca de la cúspide de Chile Trasandino. Sus bienes fueron tasados en \$23.889.16 Esta cifra era de las más altas de la región; basta señalar que, según el censo de 1739, sólo cinco vecinos de Mendoza poseían \$20.000 o más. Dentro del rubro vitivinícola, con una capacidad cercana a los 32.000 litros, la bodega de Arizmendi era la mayor de las bodegas laicas de Mendoza, junto a la de don Santiago Puebla. La actividad vitivinícola de Arizmendi floreció por sus fuertes lazos con el mercado rioplatense, siendo uno de los comerciantes más activos de la plaza. Transportaba el vino para venderlo en Buenos Aires, y desde allí traía otros productos para comerciar en Mendoza. Se ganó la confianza y el crédito de los proveedores porteños y llegó a recibir mercaderías en operaciones de fiado, otorgadas en Buenos Aires, por un monto de \$3.575. ${ }^{17}$

El liderazgo de Arizmendi como empresario se reflejó en las misiones que le encargaban los cabildos de Mendoza, San Juan y Salta en las grandes capitales de América del Sur. Para celebrar negocios y realizar gestiones, don Miguel viajaba de Santiago de Chile a Lima y de Mendoza a Buenos Aires. Allí obtenía decisiones de los gobernadores y virreyes, en función de los intereses de los empresarios vitivinícolas.

Detrás de la exitosa trayectoria empresaria de Arizmendi, latía una complicada vida emocional. Ello se reflejó en varios elementos, entre los cuales podemos distinguir principalmente cuatro: 1) su truculenta vida ascética; 2) la cercanía con las autoridades de la Inquisición; 3) la conflictiva relación con su esposa; y 4) su extraña muerte.

La vida ascética de Arizmendi también da cuenta de un profundo conflicto espiritual. Ello se nota tanto en el uso de mortificaciones corporales como en la naturaleza de sus lecturas piadosas. En efecto, las penitencias de Arizmendi incluían el uso de instrumentos de dolor físico, como cilicios y disciplinas.

16 Inventario de bienes de Miguel de Arizmendi, Mendoza, 1748. Archivo Histórico de Mendoza (en adelante AHM), Época Colonial, Sección Judicial, carpeta 233, documento 3.

17 Saguier, Eduardo. Un debate histórico inconcluso. Cuatro siglos de lucha en el espacio colonial peruano-rioplatense y en la Argentina moderna y contemporánea (2004), 14 tomos, www.er-saguier.org, apéndice B-XI, p. 1. 
Llevaba estos implementos aún en sus largos viajes, cuando sólo se transportan los objetos más indispensables. Por ejemplo, cuando viajó a Buenos Aires llevó "cuatro disciplinas y un cilicio de cintura". ${ }^{18}$

La forma de entender la espiritualidad o vida interior que trató de vivir don Miguel de Arizmendi, se puede conocer a través de sus lecturas. Como se sabe, en ese tiempo los libros eran muy escasos entre los viticultores cuyanos. En centenares de testamentos relevados, son muy escasos los libros encontrados; menos de una decena de los empresarios del vino poseía algún libro. Dentro de este contexto, don Miguel se destacaba por tener ocho ejemplares. Basta revisar sus títulos para advertir la tendencia ideológica de sus nutrientes intelectuales. Tenía un solo libro de carácter laico: El emperador Carlomagno. Todos los demás eran libros religiosos. Entre ellos había dos ejemplares de Doctrina Cristiana. También tenía tres tomos de La Mística Ciudad de Dios. Fue escrita por la religiosa de la orden de San Francisco, sor María Jesús de Agreda (1602-1665). Cargado de barroquismo, este libro alcanzó notable popularidad dentro del imperio español, particularmente para meditación.

Una parte de la biblioteca de Arizmendi estaba dedicada a obras orientadas a la búsqueda de la paz interior y a enfrentar el miedo a la muerte. Había dos ejemplares de Remedios contra los escrúpulos. También poseía un ejemplar de Ayuda a bien morir. Actualmente, este concepto está asociado con la problemática de la eutanasia. Pero en América Colonial, esta obra se empleaba para promover la esperanza en la salvación mediante una vida ajustada a las normas de la doctrina católica. Este era un texto que se difundió ampliamente en el Virreinato del Perú, sobre todo para transmitir el pensamiento y la doctrina cristiana a los pueblos indígenas. ${ }^{19}$ Arizmendi tenía también un ejemplar de La diferencia entre lo temporal y lo eterno, obra publicada originalmente en Madrid en 1640. Su autor fue el jesuita español Juan Eusebio Nierember y Otin (15951658), teólogo y ascético de notable trayectoria en la cátedra y los salones de la corte. Sus escritos trasuntaban una mezcla de

18 Inventario de bienes de Miguel de Arizmendi, Buenos Aires, 16 de enero de 1748. Archivo General de la Nación de Buenos Aires, Argentina (en adelante AGN), Tribunales Sucesiones 3859, Legajo 3, Folio 8.

19 Sabine Dedenbach-Salazar Sáenz und Frederike Meyer: Die 'Ayuda a bien morir' der Doctrina Christiana y Catecismo (Lima 1585). Übersetzung, Analyse und Kontextualisierung eines kolonialzeitlichen spanischen und Quechua-Textes aus Peru. Anthropos, International review of Anthropology and linguistics 100, 1 (2005), p. 473-493. 
escolástica con platonismo y estoicismo, con una prosa recargada al gusto del barroco.

La gravedad del pecado y la advertencia sobre las ilimitadas torturas que aguardan al hombre en el Purgatorio son los temas que Arizmendi podía aprender en otro de sus libros, Destierro de Ignorancias y aviso de penitentes y pictima del alma y arte de ayudar a bien morir. Editado por la Imprenta Real en Madrid, 1663, fue escrito por Alonso de Vascones, miembro de la Orden de Franciscanos Menores. Este libro formaba parte del corpus bibliográfico que el clero produjo en el Siglo de Oro español con vistas a consolidar la moral ortodoxa y la definición de los pecados y su gravedad. ${ }^{20}$ Esta obra informaba detalladamente de la naturaleza de los tormentos que aguardaban a las almas en el Purgatorio. Este lugar se presenta como una auténtica cárcel, en la cual se aplicaban torturas de alta intensidad; además de las consabidas llamas, tan recurrentemente representadas en la pintura religiosa del barroco europeo y americano, este libro incluía elementos particularmente impactantes; se apelaba a los sufrimientos de la pasión de Jesús como punto de partida; para purificarse y hacerse dignos de llegar a la presencia de Dios, los pecadores tendrían que recorrer un camino análogo; si Cristo sufrió la corona de espinas, los hombres también recibirían el mismo trato, pero en forma ígnea: se les pone una corona de fuego que los va apretando hasta hacerle saltar los sesos. Para brindar mayor verisimilitud a esta afirmación, fray Alonso se apoyaba en la autoridad de Santa Brígida y San Vicente. Esta forma de presentar el barroco se enmarca en las tendencias que la Iglesia impulsó después del Concilio de Trento, tendiente a consolidar el dogma del Purgatorio. ${ }^{21}$

El sentido de los sacramentos y su proyección social a través de las procesiones era otro tema de interés para Arizmendi. Particularmente, la evolución de la procesión del Corpus Christi que tuvo gran difusión en América Española. Para ilustrarse sobre este fenómeno, don Miguel tenía un ejemplar de Los corporales de Daroca. Esta obra daba cuenta del milagro ocurrido en la pequeña ciudad de Daroca (Reino de Aragón) en 1239, durante la reconquista española; la victoria obtenida por los cristianos contra los musulmanes se atribuyó a un milagro de las formas consa-

20 Elena del Río Parra, Babel y Barroco. "Hablar en lenguas" y otras manifestaciones teolingüisticas áures. Revista de Filología Española LXXXV, I (2005), p. 17-18.

21 Jacques Le Goff. El nacimiento del Purgatorio (Madrid: Taurus, 1981); Elena del Río Parra. Sacerdotes contrahechos y bautismo de locos. Sobre rituales, decisión e intención en la casuística áurea. Journal of Spanish Cultural Studies 6, 3 (october 2005), p. 289-290. 
gradas, guardadas dentro de unos corporales. Este antecedente llevó al papa Urbano IV a declarar la solemne fiesta de Corpus Christi en 1261. En el proceso que condujo a esa decisión papal tomó parte activa Santo Tomás de Aquino, promotor también del culto eucarístico a través de la composición del himno Adoro te Devote. Este libro tenía un interés muy particular para Arizmendi, no sólo porque le fortalecía la doctrina de la divinidad de la hostia, sino también porque le permitió conocer el proceso por el cual se inició, difundió y estandarizó la práctica de una procesión. Esta obra seguramente inspiró a don Miguel para poner en marcha un proceso paralelo, en el sentido de promover la tradición de las procesiones en honor de Nuestra Señora del Rosario. Estas adquirieron en Mendoza un desarrollo singular, fuertemente financiadas por Arizmendi. De esta manera creció la devoción popular por esa advocación mariana, hasta convertirla en Patrona de Mendoza por decisión del Rey y el Papa.

La relación de Arizmendi con su esposa fue intensa y desequilibrada. Cuando se casaron, en 1718, ella tenía apenas 15 años y bastante más joven que su marido, pues éste rondaba los 40 . Esta diferencia se hizo visible treinta años después. En 1748 Arizmendi era un anciano de 70 años que caminaba con un bastón y usaba un peluquín para cubrir su calvicie. Estos elementos carecían de elegancia: el bastón era de caña, y se había roto su casquillo; se valuó apenas en tres reales, lo mismo que su peluquín, que fue calificado de "viejo". 22 En cambio doña Tomasa lucía joven y bella. A pesar de tener 46 años de edad, declaró en un juicio que apenas tenía 30 , afirmación que los jueces y notarios consideraron verosímil. ${ }^{23}$

Además de la diferencia de edad, entre Miguel y Tomasa había otras distancias. Sobre todo porque el marido se dedicaba intensamente a sus asuntos industriales, comerciales, políticos y artísticos. Sus viñas y bodegas lo convocaban para obtener el refinado "vino a la vela". Los negocios lo llevaban a Buenos Aires; la acción política lo hacía ir a San Juan, Salta, Santiago de Chile, Lima y otras ciudades. Mientras tanto, su mujer permanecía en la casa, recluida en la vida doméstica, sin posibilidades de tomar parte en la administración de los negocios familiares; cuando decidió hacerlo, fue severamente castigada. Esta asimetría de roles generó una relación emocionalmente desequilibrada; Doña

22 Tasación de los bienes de Arizmendi, Buenos Aires, 1 de febrero de 1748. AGN, Tribunales Sucesiones 3859, Arizmendi Miguel, Testamentaria, Legajo 3, Folios 13 y 14.

23 Declaración de Tomasa Ponce de León, Mendoza, 6 de julio de 1748. AHM, Época Colonial Sección Judicial, Carpeta 233, Documento 4, Folio 27 v. 
Tomasa recibía escasa atención de parte de su marido, mientras que éste gozaba de saber que ella lo estaba esperando cada vez que regresaba de sus viajes para otorgarle el "descanso del guerrero".

El desequilibrio en la relación entre Arizmendi y doña Tomasa se basaba, además de la diferencia de edad y de intereses, en las tendencias bipolares de don Miguel. Así se reflejó, por ejemplo, en 1730. El verano de ese año, don Miguel estaba en Buenos Aires dedicado a sus negocios. Una vez concluida su tarea, resolvió regresar a Mendoza. Por tratarse de un viaje largo (más de 200 leguas) y peligroso (había que atravesar territorios indios), don Miguel resolvió redactar un testamento antes de viajar. Esta era una costumbre bastante habitual en la época; pero lo inusual era que un hombre casado excluyera de la herencia a su esposa y, en su lugar, nombrara su madre. En efecto, en este documento, don Miguel de Arizmendi no mencionó a doña Tomasa Ponce de León, con la cual había contraído enlace en 1718; en cambio nombró a su madre, María de Bordachepe, como única y universal heredera. ${ }^{24}$ Con el agravante que ella no vivía en América sino en Europa. Esta decisión resultaba insólita, dado que lo usual era que los vecinos residentes en las Indias, nombraran como herederos a sus parientes cercanos, sobre todo si tenían una familia directa, cono en el caso de Arizmendi. Después de redactar este extraño testamento, don Miguel atravesó las pampas y llegó a Mendoza. Una vez allí, cambió de opinión y redactó un testamento en el cual introdujo dos cambios fundamentales: nombró como albacea a su suegro, don Bernardo Ponce de León; y cambió a su madre por su esposa como heredera. ${ }^{25}$ Apenas habían pasado seis meses entre ambos documentos en los cuales don Miguel tomó decisiones tan relevantes y tan contradictorias. Algo parecido ocurrió una década más tarde: en febrero de 1746 don Miguel elaboró un nuevo documento en el cual nombraba a su mujer como albacea testamentaria; esta decisión quedó sin efecto once meses más tarde, cuando otorgó un poder para testar en beneficio del comisario de la Inquisición, el padre Francisco Correa de Saá; el testamento generado a partir de esta documento estableció como heredera a "su alma". Doña Tomasa quedaba, nuevamente, desheredada.

24 Carta de Poder otorgado por Miguel de Arizmendi, Buenos Aires, 15 de febrero de 1731. AGN, Registro de Protocolos nº 3, Esquivel, Folios 112-114 v.

25 Testamento de Miguel de Arizmendi, Mendoza, 8 de agosto de 1730. AHM, Protocolo de Escribanos nº 41 folios 132-144. 
La relación de Arizmendi con su esposa estuvo tensionada por fuertes tendencias opuestas de acercamiento y rechazo. La diferencia de edad ponía un elemento de tensión. Pero también contribuía a ello la personalidad de la mujer. El atractivo de doña Tomasa no era meramente físico. Su atracción se veía incrementada debido a su carácter apasionado. Este quedó de manifiesto en el papel activo que ella asumió en la hacienda familiar durante la ausencia de su marido por el viaje a Lima; en esa oportunidad, doña Tomasa administró los bienes, tomó decisiones, dispuso de fondos y realizó operaciones con vinos y otras especies. Esta conducta no era habitual en las mujeres casadas de la época, dado que la administración de los bienes (incluso los aportados por dote) eran administrados por el marido. A ello hay que añadir la actitud de doña Tomasa frente a su vida emocional y sexual. Basta recordar que en el mes de febrero de 1748, cuando apenas estaba llegando a Mendoza la noticia de la muerte de Arizmendi, la mujer tomó la decisión de casarse en segundas nupcias. ${ }^{26}$

La relación de don Miguel y doña Tomasa resultó conflictiva para terminar en conflicto abierto. El enfrentamiento se resolvió cuando el lado más fuerte impuso su superioridad. Doña Tomasa Ponce de León fue encerrada en una cárcel construida dentro de las chacras de don Miguel. Pero en este proceso, es importante el papel que cupo al Comisario de la Inquisición. Porque el padre Francisco conoció esta situación; así consta en el testamento que Arizmendi redactó en presencia de aquél. El clérigo ejercía una influencia moral muy grande sobre Arizmendi, y todo inclina a pensar que tuvo mucho que ver con la sucesión de conversaciones y decisiones que culminaron con el encierro de doña Tomasa. Sobre todo porque, después de la muerte de don Miguel, el padre Francisco llevó adelante acciones reales y legales contra doña Tomasa que revelaron una actitud hostil hacia ella, la misma actitud que estuvo presente en el momento de encerrarla. Por otra parte, el padre Francisco fue el beneficiario directo del conflicto entre Arizmendi y doña Tomasa. Por lo tanto, es altamente probable que haya tomado parte activa en el mismo.

Después del padre y el marido, el tercer carcelero de doña Tomasa fue el padre Francisco Correa de Saá (1703-1774), el eclesiástico con más poder que hubo en Cuyo en el siglo XVIII. Nació en

26 Arizmendi falleció en Buenos Aires el 12 de enero de 1748. La noticia demoró 45 días en llegar a Mendoza. Y casi inmediatamente, el 29 de febrero, doña Tomasa protocolizó un documento en el cual anunciaba su decisión de casarse en segundas nupcias. El matrimonio se llevó a cabo el 7 de marzo siguiente. 
el seno de una influyente familia local, en la cual se destacaron comerciantes, viticultores, transportistas y funcionarios políticos: su hermano sería Corregidor de Cuyo. Si bien el eje de la vida del padre Francisco fue la vida eclesiástica, los negocios fueron también parte importante de sus preocupaciones. Se desempeñó como administrador de haciendas, viticultor, bodeguero y traficante de esclavos. Los compraba en Buenos Aires y los vendía en los mercados chilenos. Así por ejemplo, en 1730, el padre Francisco compró a la South Sea Company ocho negros destinados al mercado de Cuyo y Chile. ${ }^{27} \mathrm{Su}$ figura creció socialmente junto con su acceso a la más esmerada educación. Su distinguida cuna le facilitó el acceso a estudios superiores para la época. Estudió en el Real Colegio de Monserrat (Córdoba) y luego en la Real Universidad de Córdoba del Tucumán, donde se graduó de bachiller, licenciado y maestro de Filosofía (1723). Luego viajó a Chile y se matriculó en el Real Convictorio de San Francisco Javier (1726). Posteriormente ingresó en la Real Universidad de San Felipe donde obtuvo los títulos de bachiller, licenciado y doctor en Sagrada Teología (1753). Además rindió Información de méritos y servicio ante el Consejo de Indias (1750). ${ }^{28}$ Paralelamente a sus estudios realizó una fulminante carrera eclesiástica en Mendoza. En esta ciudad se desempeñó como cura coadjutor, vicario foráneo y juez eclesiástico (1738-1743), cura interino (1744-1746) y cura propietario y vicario foráneo de Cuyo (1746-1776).

La exaltación del padre Francisco a la Inquisición se produjo en 1744. El 14 de abril de ese año, el Tribunal del Santo Oficio de Lima lo designó comisario en Mendoza y Cuyo, con todas las facultades y prerrogativas. Se habían cumplido apenas ocho años de la condena de los "herejes" chilenos; y todavía se hallaba preso en Lima uno de ellos, enloquecido y aislado. El padre Francisco fue comisario de la Inquisición en Mendoza durante más de 30 años, desde su nombramiento hasta el día de su muerte. Este cargo significó, para el padre Francisco, un fuerte aumento de status social dados los privilegios que le otorgaba. ${ }^{29} \mathrm{El}$ cargo de comisario convertía al padre Francisco en un actor privilegiado y, virtualmente, intocable. Pero además de sus ventajas económicas, sociales y politicas, el nombramiento tenía un significado más profundo, que

27 Elena de Studer. La trata de negros en el Río de la Plata en el siglo XVIII (Buenos Aires: Universidad de Buenos Aires, 1958); citada en René Peri Fageström. La raza negra en Chile, una presencia negada (Santiago: Lom, 1999), p. 166.

28 Lira Montt, Luis. Estudiantes cuyanos, tucumanos, rioplatenses y paraguayos en la Real Universidad de San Felipe y colegios de Santiago de Chile. Historia, 14 (1979), p. 228.

29 Lewin, La Inquisición..., p. 185. 
afectaría su forma de pensar y proceder. Al ingresar a este grupo, recibió las Instrucciones que le correspondían, y se familiarizó con los métodos represivos propios del Santo Oficio. Ello se notó en Mendoza durante la gestión del padre Francisco. Por un lado, tenemos la cárcel privada que se levantó en las chacras de don Miguel de Arizmendi para encerrar allí a su esposa. Por otra parte tenemos que considerar los instrumentos de tortura que existían en las haciendas locales. Como ejemplo se puede citar el caso de don Juan de la Cruz del Castillo; según el censo de 1739, era el hombre más rico de Mendoza, con bienes valuados en \$32.000; en su hacienda había instrumentos de tortura como "un cepo, unas esposas de fierro, cinco paras de grillos, tres grandes y dos pequeños". ${ }^{30}$ Paralelamente, en la hacienda de Santiago Puebla (1766) había "un cepo de máscara con sus esposas, de fierro". ${ }^{31}$ Estos espacios represivos no sólo existían en Mendoza, sino también en San Juan. En la hacienda de Clemente Salinas (1780) también había medios de "seguridad". Después de su muerte se realizó el inventario de sus bienes, en el cual se registró la existencia de "esposas", juntamente con "un calabozo grande con brocal de plata y otro pequeño con brocal de lo mismo". ${ }^{32}$ Paralelamente, don Luis de Benegas, segundo esposo de doña Justa de Oro, en la prolongada administración que hizo de los bienes de su mujer, también utilizó este tipo de medios para afirmar su autoridad. En efecto, entre el equipamiento de sus bodegas y viñedos había "dos pares de grillos". ${ }^{33}$ El empleo de estos medios no era exclusividad de los grandes hacendados; también los usaban los medianos y pequeños. Entre ellos cabe mencionar el caso de Fernando Juan de Cuenca, cuya bodega tenía "unos grillos" juntamente con "dos argollas de fierro". ${ }^{4}$ La Inquisición no poseía cárceles propias en Cuyo; en su lugar debía usar la cárcel pública del Cabildo o bien, las cárceles privadas de los hacendados; dado el secreto que debía rodear a sus instrucciones sumarias, parece más adecuado a sus procedimientos el empleo de las últimas, es decir, las cárceles privadas.

30 Testamentaria de don Juan de la Cruz del Castillo, Mendoza, 1 de julio de 1749. AHM, Carpeta 238, Documento 8, Folios 11 v, 15 v y 21 v.

31 Testamento de Santiago Puebla, Mendoza, 1 de marzo de 1766. AHM, Protocolo de Escribanos no 83 folio $22 \mathrm{v}$.

32 Inventario de bienes de Clemente Salinas, San Juan, 6 de mayo de 1780. AHSJ, Fondo Histórico, Libro 15, Folio 25.

33 Inventario de bienes de doña Justa de Oro, San Juan, 10 de diciembre de 1784. AHSJ, Caja 15, Carpeta 65, Documento 18, Folio 4.

34 Juicio sucesorio de Juan de la Cuenca por la muerte de su padre, Fernando Juan de Cuenca, San Juan, 10 de setiembre de 1773. AHSJ, Caja 12, Carpeta 55, Documento 2, Folio $10 \mathrm{v}$. 
La carrera eclesiástica del padre Francisco fue en continuo ascenso. En 1747 fue nombrado comisario de la Santa Cruzada, con facultades para publicar la Santa Bula y recaudar su limosna. ${ }^{35}$ Posteriormente el poder del padre Francisco se vio ampliado por la vejez y enfermedad del obispo de Santiago de Chile Juan González Melgarejo (1744-1753), lo cual le impedía realizar los viajes habituales a Mendoza para cumplir con las normales tareas de control de la actividad de las autoridades locales. Para evitarse el molesto cruce de la cordillera de los Andes, el prelado otorgó amplios poderes al padre Francisco para que realizara el trabajo en su nombre, con pleno aval de su autoridad. En este contexto le encargó:

visitéis todas las iglesias, hospitales, ermitas, capillas, altares, oratorios y demás lugares píos a Nos sujetos y que por derecho o costumbre, deben ser o por Nos o por nuestros visitadores visitados y los sagrarios y lugares donde está el Santísimo Sacramento, pilas de bautismo, crismeras y reliquias, ornamentos, aras corporales, cálices y custodias; tomando en cuenta a los mayordomos de las fábricas y colectores de Misas y cobrar los alcances; y visitar todas las memorias, aniversarios, capellanías, cofradías y obras pías, testamento y todas las demás cosas que debáis visitar y requieran visitación y hacer cumplir lo que estuviere y nombrar mayordomos y colectores, asimismo podáis inquirir y castigar los pecados públicos. $^{36}$

Con estas facultades, el padre Francisco quedaba investido de un enorme poder espiritual y a la vez, se suprimían los controles de su propia gestión dentro de la jurisdicción de Mendoza: él mismo era a la vez el vicario, juez eclesiástico y visitador eclesiástico. Dentro de estos amplios poderes que reunió Correa de Saá, hay dos que se vinculan directamente con nuestra historia: la intervención en los testamentos y la función de reprimir los escándalos públicos.

El lazo del padre Francisco con Arizmendi fue estrecho y amplio pues se proyectó a los ámbitos espirituales y materiales de la vida. En el plano comercial, el padre Francisco logró que Arizmendi lo ayudara en sus negocios de tráfico de esclavos, sobre todo para conseguir piezas en Buenos Aires y enviárselas a Mendoza. En el viaje que hizo a Buenos Aires en 1747, don Miguel adquirió varios

35 Aníbal Verdaguer. Historia Eclesiástica de Cuyo (Milán: Premiata Imprenta Salesiana, 1932), p. 1, 378-381. Relación de los méritos, grados y literatura del doctor don Francisco Correa de Saá, Madrid, 11 de marzo de 1750. Reproducido en: José Toribio Medina. Biblioteca Hispano Chilena (1573-1817) (Santiago: Fondo Histórico Bibliográfico José Toribio Medina, 1963), p. II, 487.

36 Verdaguer, Historia Eclesiástica..., p. 1, 333-334. 
esclavos para mandarlos a Mendoza. Uno de ellos lo remitió a través del tropero Fernando Jurado. ${ }^{37}$ Otros dos "negritos" los envió en las carretas de Francisco Gutiérrez, conocido en el gremio como "el andaluz". ${ }^{38}$ Tenía otro esclavo pero no lo alcanzó a enviar a Mendoza porque lo sorprendió la muerte; al hacerse el inventario de bienes se registró "un negrito llamado Antonio como de quince años que no se tasó por haber dispuesto el difunto se remitiese a Mendoza a su albacea". ${ }^{39}$ Como resultado, se entregó la "pieza" al padre Francisco.

Junto con las actividades comerciales, Arizmendi mantuvo una relación de dependencia moral muy grande hacia el padre Francisco. Este lo acompañó en los momentos de crisis y se ganó su confianza absoluta en la administración de sus bienes. Así quedó demostrado en los amplios poderes que don Miguel le otorgó al clérigo, al cual nombró también albacea y tenedor de bienes. El empresario le cedió las facultades necesarias para que el padre Francisco pudiera quedarse con la totalidad de sus haciendas. En ese sentido, la naturaleza de la relación de dependencia que Arizmendi mantuvo con Correa de Saá fue decisiva para la crisis de Miguel con su esposa y la caída de ésta en la cárcel perpetua de la pobreza.

El cuarto carcelero de doña Tomasa fue el cazador de viudas. Este fue el papel que cupo a don José Rodríguez de Arellano y Esclava, español peninsular con amplia trayectoria en el Cono Sur de América, en la cual intentó varias veces conquistar una viuda rica.

En cuanto marido, don José era muy distinto a don Miguel. Si éste era rico, aquel no tenía bienes ni prestigio, pero sí juventud y un espíritu alegre y despreocupado. Era, esencialmente, un seductor, capaz de ganarse la confianza de doña Tomasa Ponce de León y convencerla de celebrar una boda, con el propósito de luchar por el control de la hacienda de Arizmendi. Éste era el móvil de José y no era la primera vez que entablaba un lazo amoroso con una viuda. Tenía experiencia en el tema. Su plan avanzó, paso a paso, hasta que, al ver la inviabilidad del acceso a la riqueza, perdió todo el interés por doña Tomasa.

José Miguel Rodríguez de Arellano y Esclava era un español peninsular, natural de Guipúzcoa. En 1741, cuando "tenía muy

37 Declaración de Fernando Jurado, vecino de Mendoza; Mendoza, 27 de abril de 1748. AHM, Época Colonial Sección Judicial, Carpeta 233, Documento 4, Folio 48 v.

38 Declaración de Juan Silva, 29 de abril de 1741. AHM, Época Colonial Sección Judicial, Carpeta 233, Documento 4, Folio 52 v.

39 Tasación de bienes de Miguel de Arizmendi, Buenos Aires, 1 de febrero de 1748. AGN, Tribunales Sucesiones 3859, Legajo 3, Folio 14. 
corta edad", zarpó de Cádiz rumbo a América. ${ }^{40}$ Era un hombre de educación elevada para la época, dado que sabía leer y escribir. Sus andanzas lo llevaron por distintas ciudades de América del Sur. En 1745 vivió en Lima y luego en Cuzco. Más tarde se instaló en el Alto Perú, particularmente en Chuquisaca y Potosí. Allí estuvo a punto de casarse con María Álvarez, viuda de Juan de Santa Lisis. Corrieron rumores de este amor del joven y la viuda, pero el matrimonio no se concretó. Posteriormente viajó al sur, estuvo en Salta y en Córdoba. ${ }^{41}$

La relación con doña Tomasa fue muy rápida y fugaz. José llegó a Mendoza cuando Arizmendi estaba de viaje en Buenos Aires. Rápidamente tuvo noticias de sus afamados vinos y sus magníficas haciendas. Entonces advirtió que podía haber allí una buena oportunidad. Sobre todo porque doña Tomasa era una candidata bastante accesible: después de tantos años casada con un hombre mayor, podía resultarle atractiva la idea de formar pareja con un hombre joven. Además, si Arizmendi era una persona muy entregada a sus negocios y casi obsesiva en sus métodos de elaboración del vino y en sus talleres, José podía brindarle atención e interés, lo cual podía ser también atrayente para la mujer. Doña Tomasa encontró todo ello en José Rodríguez, que no tenía más bienes que su juventud, la experiencia de sus viajes, su cultura y su vida alegre.

Por su parte, para don José, Tomasa representaba lo que estaba buscando desde antes: una viuda con recursos económicos. Ya había intentado desposar una mujer así en Potosí, sin éxito. Luego trató de poner en marcha su propia empresa, con una tienda en Córdoba, pero le duró poco. Al llegar a Mendoza se encontró con una viuda, relativamente bella - a pesar de sus años - y con derechos a una hacienda importante.

En estas circunstancias, los hechos se precipitaron. Arizmendi murió en Buenos Aires el 9 de enero de 1748. La noticia demoró 45 días en llegar a Mendoza e inmediatamente, el 29 de febrero, doña Tomasa anunció la decisión de casarse con José; la boda se celebró el 7 de marzo. Poco después, José Rodríguez de Arellano se

40 Declaración testimonial de José Mesías, natural de Valencia, para informe de soltería de José Rodríguez; Mendoza, 8 de marzo de 1748. Archivo del Arzobispado de Mendoza (en adelante AAM), Informaciones Matrimoniales, Parroquia Matriz de Mendoza, año 1747-1748, Folio 128.

41 Declaración testimonial de Hilario de los Ríos, natural de Chuquisaca, para informe de soltería de José Rodríguez, Mendoza, 8 de marzo de 1748. Archivo del Arzobispado de Mendoza (en adelante AAM), Informaciones Matrimoniales, Parroquia Matriz de Mendoza, año 1747-1748, Folio 128. 
presentó a la justicia en representación de su esposa, para reclamar los bienes de la hacienda de Arizmendi. De allí en adelante se puso en marcha un largo pleito por la hacienda.

La decisión de doña Tomasa, en el sentido de casarse en esas circunstancias, marca una actitud transgresora y gozadora. Lo que hizo fue exactamente lo contrario a su primer matrimonio. En esa oportunidad, su novio fue un hombre 25 años mayor, de alto nivel social, claramente conveniente para una familia de la élite. Ella tenía 15 años y la decisión fue tomada, en buena medida, por influencia paterna. En cambio, en el segundo matrimonio, su padre ya había fallecido y no había autoridades sobre ella. Fue la oportunidad de decidir por sí misma.

El segundo esposo de Tomasa fue exactamente opuesto al primero. Este le fue impuesto por los padres a los 15 años de edad; aquel lo eligió ella, cuando tenía 46. Arizmendi era un buen partido y le aseguraba una vida socialmente distinguida $y$ materialmente confortable. En cambio Rodríguez era impredecible y no podía atraer a nadie por cálculos de bienestar o seguridad económica. Doña Tomasa sabía que, en su precaria situación, casarse con un hombre así podía significarle una vida de incertidumbre para su futura vejez, tal como finalmente ocurrió. No obstante ello, fue la decisión que ella tomó. Y jugó fuerte siguiendo exclusivamente su deseo, sin dudar en transgredir los usos y costumbres de la época.

El matrimonio de Tomasa con José fue transgresor por tres razones. Primero, no guardó el período mínimo de duelo que se estilaba en ese tiempo; "no dejó enfriar el cadáver de su marido", para usar una expresión popular en el Reino de Chile. Segundo, su novio no pertenecía a la élite; era socialmente de inferior rango. Tercero, su novio era un hombre notablemente más joven, situación poco habitual en la época porque las viudas de hacendados, por lo general, buscaban un hombre de experiencia, capaz de administrar los bienes recibidos, y no un aprendiz. Como la virtud principal de José era su juventud, social y culturalmente no era muy fácil de explicar que doña Tomasa estaba posponiendo los valores tradicionales por el deseo que le despertaba el joven español.

La situación social de José Rodríguez de Arellano se acercaba a la indigencia. Carecía de los medios para satisfacer las necesidades más elementales de vestido y alimento. Doña Tomasa debió apelar a lo que le quedaba de su prestigio para que le facilitaran los medios de vestirse y comer. Para poder casarse con un mínimo de dignidad, ni ella ni el novio tenían ropas adecuadas 
ni dinero. La mujer se vio en la necesidad de pedir prestado a sus antiguos amigos de la élite. Esta tarea no fue fácil y debió humillarse para suplicar por esa ayuda. Finalmente la consiguió de parte del sargento mayor José de Quevedo; pero éste le exigió a cambio, una Carta de Obligación en la cual se dejaba constancia del préstamo, con el compromiso de devolverlo en dos meses. En este documento se hizo evidente la falta total de recursos de José Rodríguez. Doña Tomasa señaló que

quiere contraer matrimonio en segundas nupcias con don Joseph Rodríguez, y porque se halla al presente así ella como él dicho su marido, que ha de ser con algunas necesidades, así de vestuario como de otras cosas muy necesarias, y que por la confiar [sic] y satisfacción que tiene la susodicha de la persona del sargento mayor don Joseph de Quevedo, ha suplicado que le favorezca en suplirle todo aquello que hubiere menester, así para ella como para la decencia de don José Rodríguez, otorgándole escritura de pagarle todo aquello que le supliese y ... por la cuenta que dicho don Joseph Quevedo formase de los suplementos que hiciere, así en plata como en géneros de Castilla y que pagará dentro de dos meses. ${ }^{42}$

La escasez de medios del novio no fue una situación coyuntural de ese momento. Dos meses más tarde, se dirigió a la justicia para solicitar una pensión alimentaria, mientras tanto se sustanciara el pleito de doña Tomasa contra el padre Francisco por el control de la hacienda de Arizmendi. La respuesta inmediata de la justicia fue ordenar al tenedor de bienes que se le entregaran seis reales diarios al nuevo matrimonio como cuota alimentaria. ${ }^{43}$ Estos documentos demuestran el nivel económico en que estaba José Rodríguez de Arellano: estaba en la indigencia.

La decisión de doña Tomasa, en el sentido de desposar a un hombre que no le ofrecía ninguna seguridad económica, revela otro aspecto de su intimidad: la mujer se casaba con él exclusivamente porque lo deseaba. Bella, apasionada, deseosa de gozar la vida. Así era ella. Gran constraste se marcaba con su ex marido, don Miguel, el cual era todo lo contrario: trabajaba como si fuera un neurótico obsesivo; estaba atormentado por los escrúpulos y realizaba mortificaciones corporales como penitencia para calmar sus culpas.

Las grandes expectativas de hallar un amor apasionado que vivió doña Tomasa en el verano de 1748, pronto se vieron frustradas. Su joven marido apenas se mantuvo a su lado durante

42 Carta de obligación de doña Tomasa Ponce de León, Mendoza, 29 de febrero de 1738. AHM, Protocolo de Escribanos № 53 Folio 47 v - 48.

43 Presentación judicial de José Rodríguez de Arellano, Mendoza, 26 de mayo de 1748. 
unos meses. Inicialmente, José le brindó una esperanza de felicidad, a la vez que se ilusionó con la idea de ganar la hacienda de Arizmendi. Por ello se casó con doña Tomasa y poco después, inició acciones legales para solicitar la propiedad. El 19 de junio de 1748, acompañó a su mujer a reclamar los bienes. En este trámite, ella no pudo firmar por ser analfabeta. Entonces, "a ruego de doña Tomasa Ponce de León" firmó don José Rodríguez de Arellano. ${ }^{44}$ Esos fueron días felices para la mujer: gozaba de la compañía de su joven pareja y su apoyo para enfrentar al padre Francisco. Pero el español no tenía mucha paciencia. Pronto advirtió que la tarea se presentaba con pobres perspectivas. El poder del clérigo era incontrastable. $\mathrm{Ni}$ el corregidor ni los jueces se atrevían a enfrentarlo. Comprobada esta situación, José se vio ante la disyuntiva: o se quedaba junto a Tomasa, a pesar de la escasez de recursos económicos y honraba su compromiso de amor; o la abandonaba a su suerte, y se iba en busca de nuevas aventuras. Optó por este segundo camino. Un mes más tarde, el 6 de julio, doña Tomasa tuvo que asistir de nuevo a la justicia a declarar pero esta vez, no estuvo a su lado su segundo marido. Simplemente, "no firmó por no saber". 45 Con posterioridad a esta fecha, no se han hallado más rastros de la presencia de José Rodríguez de Arellano, ni junto a doña Tomasa, ni en la ciudad. Despareció literalmente de Mendoza. Para él, el matrimonio de doña Tomasa fue una aventura más en su vida. Posiblemente, siguió recorriendo América en busca de aventuras y viudas ricas. Pero, para la mujer, fue un revés importante.

Una nueva etapa en la vida de doña Tomasa comenzó en julio de 1748. A partir de entonces, su segundo marido desapareció de su lado y ella quedó en una situación sensiblemente deteriorada: además de viuda desheredada, se convertía también en esposa abandonada. Esta situación tenía un alto costo emocional para ella, dadas las ilusiones que se había forjado. Además, dado el carácter indisoluble del matrimonio para la cultura hispano-católica, ya no tenía la posibilidad de entablar una nueva relación legítima, porque había utilizado la única oportunidad que le quedaba; tampoco estaba culturalmente preparada para afrontar su vida en forma autónoma desde el punto de vista económico, pues no había desarrollado un oficio ni tenía los bienes que le correspondían. Su hacienda quedó definitivamente en manos del

44 Declaración de Tomasa Ponce de León, Mendoza, 19 de junio de 1748. AHM, Época Colonial, Sección Judicial, Carpeta 233, Documento 4, Folio 157 v.

45 Declaración de Tomasa Ponce de León, Mendoza, 6 de julio de 1748. AHM, Época Colonial Sección Judicial, Carpeta 233, Documento 4, Folio 27 v. 
padre Francisco. Y ella debía resignarse a entrar a una nueva cárcel - ahora en forma definitiva. No era una prisión física sino socioeconómica: quedaba encerrada en la pobreza, sin posibilidades de salir de allí.

La estadía de doña Tomasa en esta fría cárcel, llamada pobreza, tuvo dos carceleros. Uno de ellos, tuvo este papel por omisión: don José Rodríguez fue responsable de este encierro de Tomasa por su actitud de utilizarla como un medio, en vez de amarla como un fin en sí misma. No fue capaz de amar a la persona; se casó con ella para instrumentalizarla. Y luego la abandonó, sin brindarle el cuidado que le había prometido en el matrimonio. El otro carcelero fue el padre Francisco, que logró tenerla siempre alejada de la hacienda de Arizmendi, la cual él usufructo. Como resultado logró una vida de comodidades para él, y ricas sumas para dedicar al culto divino, en el marco del barroco americano y sus necesidades de revestir de pompa y esplendor las manifestaciones de arte religioso.

Comparando a los carceleros entre sí, surgen algunas diferencias. El cazador de viudas y el clérigo exhibieron frialdad e indiferencia hacia la mujer. La veían como una cosa, un medio, más que una persona o un sujeto. En el caso de don José, el más frívolo y desideologizado de los tres, el objetivo era su beneficio individual. Para el padre Francisco, en cambio, la dureza de su trato hacia doña Tomasa estaba justificada por actuarse ad major gloria Dei. El clérigo estaba cumpliendo las consignas del obispo de Santiago y del Concilio de Trento, en el sentido de tener un gran espíritu de recogimiento y recocer todos los bienes posibles para elevarlos al servicio de Dios. Los dolores humanos quedaban plenamente justificados en la medida que se podían entregar dones a Dios. Y para Dios, todo es poco. En otras palabras, el padre Francisco había actuado como una máquina fría, pero perfectamente programada para actuar así.

El enfoque de Arizmendi tuvo sus propios elementos. Por un lado, la influencia del padre Francisco y la bibliografía disponible, tendía a impulsarlo a actuar con la misma lógica fría que el clérigo. Pero don Miguel tenía otras sensibilidades. A pesar de los condicionamientos ideológicos, don Miguel tuvo un intenso lazo emocional con su esposa En sus viajes solía comprarle vestidos y objetos decorativos para la casa. Los inventarios de sus propiedades muestran una notable acumulación de prendas femeninas de cierta elegancia. Incluso después de la crisis matrimonial y la ruptura, don Miguel pensaba en ella y, a su modo, la amaba. Ni el tiempo ni la distancia le permitieron olvidarla. Al encontrarse en 
Buenos Aires, y sabiéndose cerca de la muerte, don Miguel expresó su voluntad de hacerle obsequios. Ordenó mandarle, por ejemplo, "una colcha de angaripola forrada en listadillo". ${ }^{46}$ Además, los albaceas, siguiendo seguramente sus instrucciones, remitieron a doña Tomasa "ocho sábanas usadas con toda la demás ropa perteneciente a su cama", juntamente con "seis fundas usadas". ${ }^{47}$ Además, don Miguel ya había enviado rumbo a Mendoza algunos regalos y joyas que, probablemente, estaban destinados a doña Tomasa. Entre ellos había dos sortijas de piedras de esmeraldas engastadas en oro. ${ }^{48}$ Evidentemente, las sortijas eran algo personal de Arizmendi, destinado a la persona de sus amores.

La actitud de Arizmendi, en el sentido de preocuparse por el bienestar de su mujer y enviarle ropas a pesar de la ruptura, contrastaba con la posición fijada por el padre Francisco. Tal como se ha examinado antes, en ese mismo verano de 1748, en el cual Arizmendi trataba de acercarle algún obsequio a su esposa, el clérigo le negaba todo socorro. Doña Tomasa estaba pasando serias privaciones y llegó a tener que suplicar ayuda para poder vestir en forma decente en su segundo casamiento. ${ }^{49}$ La situación material de doña Tomasa cambió definitivamente después de la muerte de Arizmendi. El padre Francisco tomó el control total de las haciendas, y operó hábilmente en los estrados judiciales para excluirla de todos los derechos que le correspondían por gananciales. Como resultado, doña Tomasa vivió una larga vida de privaciones hasta que murió en la pobreza. ${ }^{50}$ En cambio el clérigo

46 Inventario de bienes de Miguel de Arizmendi, Buenos Aires, 16 de enero de 1748. AGN, Tribunales Sucesiones 3859, Legajo 3, Folio 6; Tasación de bienes de Miguel de Arizmendi, Buenos Aires, 1 de febrero de 1748. AGN, Tribunales Sucesiones 3859, Legajo 3, Folio 11.

47 Tasación de bienes de Miguel de Arizmendi, Buenos Aires, 1 de febrero de 1748. AGN, Tribunales Sucesiones 3859, Legajo 3, Folio $10 \mathrm{v}$.

48 Las llevó el tropero Fernando Jurado sin ser notificado de un destinatario específico para entregarle estos objetos. Declaración de Fernando Jurado, Mendoza, 24 de julio de 1748. AHM, Época Colonial Sección Judicial, Carpeta 233, Documento 4, Folio 48 v. Esta situación contrastaba con otros bienes que Arizmendi remitió a Mendoza, con el destinatario indicado a los troperos. Por ejemplo, una carga de dos costales de cebo, con peso de 19 arrobas y 8 libras, juntamente con seis barriles de fierro con peso de 11 arrobas, debían entregarse a don Pedro Ortiz de Quintana, junto con una carta póstuma que don Miguel le escribió. Declaración del Maestre de Campo José Méndez de Sanjurjo, Mendoza, 29 de abril de 1748. AHM, Época Colonial Sección Judicial, Carpeta 233, Documento 4, Folio $50 \mathrm{v}$.

49 Carta de Obligación de doña Tomasa Ponce de León, Mendoza, 29 de febrero de 1748. AHM, Protocolo de Escribanos no 53, Folio 48.

50 Doña Tomasa falleció en 1772, a los 69 años de edad. En el acta correspondiente se consigna que "No testó por ser pobre". Acta de defunción de doña Tomasa, dada en 
gozó de una vida opulenta, llena de comodidades, y murió rodeado de bienes que se podrían considerar lujosos para la época. ${ }^{51}$

Había contradicciones en el corazón de Arizmendi; por un lado, se sentía atraído por el amor de su mujer; por otro, la influencia del padre Francisco lo llevaba a alejarse de ella. El resultado de estas fuerzas contradictorias fue una sensible tensión emocional que lo llevó a la muerte. En este punto conviene detenerse.

La salud física de Arizmendi era buena en 1747. A pesar de haber llegado recientemente de su largo viaje por la cordillera de los Andes y el Pacífico, don Miguel hizo una nueva travesía: recorrió más de 200 leguas para llegar a Buenos Aires. Allí realizó una intensa actividad comercial y política. Cerró negocios, vendió vinos, compró esclavos, equipamiento, productos comerciales, muebles y joyas. Contrató troperos y arrieros para remitir estos bienes hacia Cuyo. Además, dedicó tiempo a las negociaciones políticas al más alto nivel, para coordinar acciones de los intereses de los empresarios y las autoridades estatales de todo el Cono Sur. Entre sus papeles de trabajo se encontró

un despacho del señor Virrey (del Perú) y otro del Cabildo de Mendoza, con la copia de la carta escrita a éste gobierno (de Buenos Aires) y un apunte de algunas advertencias que hizo (Arizmendi) en la víspera de su fallecimiento, y un tanto del Acuerdo que se tomó en el Cabildo de Salta, para la imposición de los nuevos arbitrios, sobre la defensa de la Provincia y una Instrucción de las diligencias que deberá ejecutar (Arizmendi) en la incumbencia que estaba a su cuidado. 52

El documento demuestra que, hasta un día antes de morir, don Miguel de Arizmendi era protagonista de las redes socioeconómicas y políticas del Cono Sur al más alto nivel. El empresario manejaba negociaciones entre cabildos y gobernantes en temas tan delicados como políticas impositivas. Evidentemente, si los organismos públicos de la región le permitían tomar parte de estos espacios de poder, era porque Arizmendi tenía las capacidades necesarias para ello. Por lo tanto, Arizmendi no murió como resultado de un natural proceso de deterioro de su salud física. Su

Mendoza, el 28 de enero de 1772. Archivo del Arzobispado de Mendoza. Libro de defunciones de la Parroquia Matriz de Mendoza, № 3 A, folio 241v.

51 Testamento del padre Francisco Correa de Saá, Mendoza, 9 de agosto de 1775. Reproducido completo en: Mariano Marcó. Quién era quién en Mendoza. Ïndice de los Testamentos en Actuaciones Notariales. Tomo I: 1561-1810 (Mendoza, edición de autor, 1998), p. 313-321.

52 Inventario de bienes de Miguel de Arizmendi, Buenos Aires, 18 de enero de 1748. AGN, Tribunales sucesiones, 3859, Legajo 3, Folio $7 \mathrm{v}$. 
problema no fue una enfermedad del cuerpo, sino resultado de una fuerte tensión emocional.

Para comprender la muerte de Arizmendi, conviene repasar los últimos movimientos de su vida privada. Tras regresar de Lima (otoño de 1746), se produjo el conflicto con su esposa, que culminó con el encierro de ella. Influido por el padre Francisco, don Miguel se convirtió en carcelero de doña Tomasa. Pero esta situación se le hizo emocionalmente insoportable $\mathrm{y}$, a pesar de su reciente viaje a Chile y Perú, emprendió uno nuevo, esta vez, a Buenos Aires. Allí no encontró la paz; por eso tenía consigo sus instrumentos de mortificación corporal. Hizo negocios con fines comerciales, como la compra y el envío a Mendoza de bienes destinados a sus clientes y socios. Pero también tomó decisiones personales. Compró regalos, muebles y joyas (sortijas con esmeraldas) y las mandó a Mendoza para ejecutar un plan personal. Los documentos inclinan a pensar que don Miguel buscaba la forma reconciliarse con su esposa. Deseaba encontrarse con ella y reconciliarse. Para realizar este deseo, Arizmendi debía salir de su propia cárcel mental, y enfrentar a su vez, a su propio carcelero, el padre Francisco. Y esto no fue posible. La tensión entre su deseo y la imposibilidad de realizarlo, agudizó su conflicto emocional y desencadenó su muerte.

La traumática historia de Arizmendi y doña Tomasa causó un fuerte impacto en el medio. Tal como ocurrió en Santiago de Chile con el apasionado romance entre el arquitecto Toesca y su esposa, el conflicto generó comentarios en todas las capas sociales. En las pulperías, las postas y en los fogones de los arrieros y troperos se comentaban detalles de figuras tan conocidas. Así se refleja en los expedientes judiciales que se formaron con motivo de los pleitos sucesorio. La magnitud de los acontecimientos y lo encumbrado de sus protagonistas, justificaron que estos temas se mantuvieran vigentes durante bastante tiempo. El folklore se apropió de esta historia y terminó por expresarla en la zamba Luna Cautiva, que da cuenta de una mujer encerrada en una prisión, y el dolor de su marido que la ama y no puede liberarla.

Tal como reflejan esta canción y los hechos analizados, la relación entre el carcelero y la prisionera, entre el victimario y la víctima, fue intercambiable. Porque, en el fondo, no se sabe bien quién estaba encerrado. El carcelero era, posiblemente, el que tenía la prisión más rígida; sus muros no eran bloques de materia, sino representaciones mentales. Estaba prisionero del terror que le producían el pecado y el Purgatorio; de las culpas y penas que debía pagar por ellas. 
El caso de doña Tomasa Ponce de León y sus carceleros, ha permitido observar el funcionamiento el sistema. La mujer estaba predestinada a vivir en el marco de relaciones de subordinación con un conjunto de varones, que tomaban decisiones por ella, y constantemente la sujetaban, le limitaban la posibilidad de movimientos, y la confinaban en las sucesivas prisiones. El padre la encerraba en su casa, y la obligaba a casarse con un candidato 25 años mayor que ella. Tras el casamiento, el marido mantuvo la situación de autoridad y encierro doméstico. La autoridad de estos dos carceleros era reforzada por la acción del tercero: el clérigo. Éste operaba sobre la mujer (y sus carceleros) con la amenaza del purgatorio, que funcionaba como un presidio dotado de atroces tormentos. La influencia moral del clérigo, con el poder disuasivo de aquella cárcel sobrenatural, no hacía más que reforzar la autoridad del clero sobre el varón y del éste sobre la mujer, y engrosaba las murallas del presidio doméstico.

Es importante señalar que, así como la mujer estaba condicionada por el entorno cultural a ser víctima, los hombres también estaban programados para actuar como victimarios. La cultura dominante les imponía la necesidad de actuar de esa manera. El padre no podía tolerar que su hija decidiera por sí misma; el marido tampoco podía comprender o perdonar a su mujer, si ésta tomaba iniciativas sin su permiso o si le era infiel. Debía castigarla severamente, para salvar su honor. La mujer carecía de honor; éste era propiedad exclusiva del hombre. Era como una suerte de herencia recibida con su identidad de género, y se debía defender a todo trance. Aún en el caso extremo de tener que encarcelar a la mujer amada, y morir luego de dolor por ello. En su cárcel mental, el hombre estaba preso de valores como el honor, que lo oprimían, controlaban y dominaban, hasta llevarlo a ejecutar acciones que, en el fondo de su corazón humano, repudiaba. El dolor de Arizmendi por el encierro de su mujer amada, su "Luna Cautiva", fue un reflejo de esta situación. A pesar de su poder económico, político y militar, don Miguel no tenía reservas emocionales para revelarse contra la autoridad del clérigo, y se convirtió en el victimario de su esposa, y en última instancia de sí mismo. El carcelero estaba a su vez, encerrado en una cárcel ideológica, de la cual no podía salir, pues sus muros eran más sólidos que las paredes materiales de un presidio físico.

El encierro femenino parecía tener fin cuando la mujer quedaba viuda. Como por encanto, buena parte del poder que limitaba sus movimientos, se desvanecía. La mujer quedaba en condiciones de iniciar una nueva vida, sin tener que rendir cuentas 
a nadie y con plena capacidad de tomar sus propias decisiones. En este contexto, podía aparecer un cuarto actor social, capaz de volver a encerrarla, pero en una cárcel sin retorno. La figura del cazador de viudas, hasta ahora poco considerada por la literatura especializada, fue también relevante en el espacio colonial. En el caso estudiado, se trata de un personaje muy móvil, con algún capital cultural (en el caso de José Rodríguez, la fortaleza se hallaba en su condición de español peninsular y la experiencia de largos viajes). Después de largos años de vivir subordinada a un padre autoritario y un marido de más edad, la mujer entraba a la viudez con necesidades emocionales y sexuales insatisfechas. En ese contexto, la perspectiva de un compañero joven y sin mayores preocupaciones por sostener un emprendimiento productivo, era una alternativa atrayente para la mujer. Pero se corría el riego de, en poco tiempo, descubrir que se trataba de un cazador de viudas, apenas interesado en el beneficio económico a corto plazo; y que no dudaría en abandonarla, encerrada en la pobreza. Esta sería la última prisión, en la cual terminaba la mujer, en un proceso en el cual volvía a tomar parte activa el clérigo.

El clérigo, siempre el clérigo; allí estaba para levantar más paredes que puentes. Para fortalecer autoridades y para reducir libertades. Pero más allá del caso personal estudiado, este actor social también estaba condicionado por la cultura dominante. Basta considerar la doctrina del Concilio de Trento, el impulso del Barroco como arte de la Contrarreforma y las instrucciones episcopales. El clérigo debía reprimir los escándalos y conseguir recursos para destinar al culto: el sentido de los bienes terrenales era dedicarlos ad maiorem Gloriam Dei. Si el autor le escribió el libreto, el actor (el padre Francisco) lo ejecutó fielmente. En otras palabras, el clérigo también era un carcelero condicionado o programado para actuar como tal. Las fuerzas que oprimían a la mujer colonial latinoamericana, no era un conjunto de personas individuales, sino una estructura ideológica ampliamente difundida a través de las instituciones políticas y eclesiásticas del imperio español.

Recebido em 23 de março de 2007. 